\title{
Technologies used for food preservation using microwaves
}

\author{
Elena Sorică, ${ }^{1 *}$, Cristian Marian Sorică ${ }^{1}$, Mario Cristea ${ }^{1}$, and Iulia Andreea Grigore ${ }^{1}$ \\ ${ }^{1}$ INMA National Institute of Research - Development for Machines and Installations designed to \\ Agriculture and Food Industry, Bucharest, Romania
}

\begin{abstract}
Food preservation is the process of treating food, with the aim of preserving its qualities for as long as possible. Extending the freshness period for processed foods has been and is a continuing challenge for producers in the food industry. New technologies and conservation methodologies are continuously researched, which will have as little effect as possible on the nutritional value of the products. Microwave food processing is constantly evolving, rapid heating and high energy efficiency are the major advantages of using this technology. The paper presents a study regarding the preservation of food products using microwaves, its acting mechanism and other applications of microwaves for food processing, as well as some installations and equipment that use this technology.
\end{abstract}

\section{Introduction}

Use The food industry has experienced a constant development in recent years, and has been identified so far different methods and techniques for food preservation [1].

Even though many food preservation methods have been developed over time, most of the current approaches may impact the quality of foods and/or change the regular form and aspect [2].

The preservation of food products, including those from the vegetable - horticultural sector, is performed according to a series of principles and methods that involve compliance with certain technologies depending on the purpose of the method [3].

Among the newest and most modern methods of preservation we mention the athermic and thermal ones which are different from the classical methods.

The most important athermic preservation methods are:

- preservation using high pressures;

- preservation using the magnetic field;

- preservation using ionizing radiation;

- preservation using the pulsating magnetic field;

- preservation using ultra-short light pulses;

\footnotetext{
* Corresponding author: postelnicu.elena@yahoo.com
} 
- preservation using ultraviolet radiation.

The most important thermal preservation methods are:

- preservation by microwave heating;

- preservation by ohmic heating;

- conservation by heating with radio frequency waves;

- preservation by indirect heating with Joule effect (actiJoule) [4].

Microwave heating is an emerging alternative direct heating method [5].

Microwaves are high frequency electromagnetic radiation, ranging from $300 \mathrm{MHz}$ to $300 \mathrm{GHz}$ and having wavelengths between $1 \mathrm{~m}$ and $1 \mathrm{~mm}$, therefore are ranked among radio waves. Their existence was first mathematically assumed by Maxwell, then experimentally verified in 1885 by Hertz [6].

Fast heating and high energy efficiency are the major advantages of using microwaves in food processing [7].

When used for heating microwaves have significant advantages over conventional methods, due to the volumetric manner in which they generate heat which leads to a more rapid heating compared to conventional methods, particularly when it comes to solid foods [8].

Other notable advantages are: space saving, a better process control, selective heating and a better preservation of the nutritional quality of food. There are however some problems with preserving several properties of the food with this technology and the fact that uneven heating usually occurs [7].

In order to overcome these challenges, especially nonuniform heating, various solutions have been proposed including proper selection of packaging materials, using optimization tools to obtain the best processing parameters as well as holding materials in constant motions corresponding to uniform microwave power absorbed in the cavity, thereby preventing cold/hot regions [9].

Microwave heating can be applied to various food processing operations, namely, drying, baking, roasting, blanching, pasteurization, and sterilization [10].

\section{Mechanism and applications of microwaves for food preserving}

The microwave heating mechanism differs from other types of heating. The differences may or may not be beneficial depending on the process in which the microwaves are used. For example, the fact that microwave heating time is short is to the advantage of food processing, because nutrient losses are minimal. On the other hand, for bakery products, this aspect becomes negative, because this time interval is not enough for the biochemical reactions to take place in optimal conditions.

To understand the mechanism of microwave heating it is needed to understand the dielectric properties of food. The dielectric properties of food can be assessed according to the value of the dielectric constant $\left(\varepsilon^{\prime}\right)$ and the loss factor $\left(\varepsilon^{\prime \prime}\right)$. The dielectric constant is the real part, and the loss factor is the theoretical part of the complex permittivity $\varepsilon_{\mathrm{r}}$, which is defined by the following relation:

$$
\varepsilon_{r}=\varepsilon^{\prime}-j \varepsilon^{\prime}
$$

The dielectric constant expresses the property of the material to store microwave energy, while the dielectric loss factor is correlated with the ability of the material to dissipate microwave energy in the form of heat. The dielectric properties of foods depend 
on their composition, temperature and frequency. There are currently data on dielectric constants for many foods such as fruits and vegetables, meat and ham, starch and glucose solutions, various food proteins, and some types of pasta.

However, there is less data on the dielectric properties of frozen foods, as well as for foods found at temperatures above the boiling point of water. If the frozen foods are important for thawing or tempering processes, the temperatures above the boiling point of water are needed for the use of microwaves for pasteurization and sterilization. Such measurements were made for protein gel from whey, macaroni and cheese mixes at temperatures between $20-121^{\circ} \mathrm{C}$ and at frequencies of $27,40,915$ and $1800 \mathrm{MHz}$. The dielectric properties of food can also be used to control the quality of products. Therefore, microwaves can be used to determine the freshness of the fish, the quality of the frying oil, etc. The dielectric properties give a quick indication of the moisture content of agricultural products. Dielectric measurements can be used to distinguish the bound water from free water.

The density of the thermal power generated by a microwave field is given by the following formula:

$$
P_{1}=5.56 .10^{-12} f \cdot E^{2} \cdot \varepsilon^{\prime \prime}
$$

where P1 is the density of the thermal power $(\mathrm{W} / \mathrm{m} 3)$, f - the frequency of the microwave field $(\mathrm{Hz})$, (generally $2.45 \mathrm{MHz}$ ), E - the intensity of the electric field (V/ m) and $\varepsilon$ "- the dielectric loss factor of food (the imaginary part of the complex dielectric constant).

The dielectric loss factor of food is a measure that characterize the possibility to transform microwave energy into heat. When electromagnetic waves come in contact with the dielectric (with the food product), a part of the energy will be reflected and the other will enter the product where it will gradually attenuate, turning into heat. The depth of microwave penetration (d) into food depends on both the dielectric constant of the food and the loss factor, according to the following formula:

$$
d=\frac{0,1125 \cdot \lambda_{0}}{\sqrt{\sqrt{\left(\varepsilon^{\prime}\right)^{2}+\left(\varepsilon^{\prime \prime}\right)^{2}-\varepsilon^{\prime}}}} \text { or } d=\frac{0,159 \cdot \lambda_{0} \cdot \sqrt{\varepsilon^{\prime}}}{\varepsilon^{\prime \prime}} \text { if } \varepsilon^{\prime \prime}<<\varepsilon^{\prime}
$$

where $\lambda_{0}$ is the wavelength of the microwave in a vacuum $(12,2 \mathrm{~cm} \mathrm{la} 2,45 \mathrm{GHz})$. The two formulas show the importance of the dielectric properties $\varepsilon$ "and $\varepsilon$ 'on the microwavefood interaction. Some relevant values of these properties, found at the frequency $2.45 \mathrm{GHz}$ are presented in table 1 .

The loss factor, $\varepsilon$ ", increases significantly with product moisture and salt concentration. As can be seen in Table 1, the ice loss factor is very small, which causes a food loss factor to increase significantly over time. Fats and oils do not absorb microwaves well [7].

Table 1. Dielectric properties of foods [7]

\begin{tabular}{|l|c|c|c|}
\hline \multicolumn{1}{|c|}{ Product $\left.\mathbf{( 2 5}^{\mathbf{0}} \mathbf{C}\right)$} & $\boldsymbol{\varepsilon}^{\prime}$ & $\boldsymbol{\varepsilon}^{\prime \prime}$ & Penetration depth \\
\hline Beef & 61 & 17 & $9 \mathrm{~mm}$ \\
Pork & 58 & 16 & $9 \mathrm{~mm}$ \\
Potatoes & 64 & 14 & $11 \mathrm{~mm}$ \\
Carrot & 72 & 15 & $11 \mathrm{~mm}$ \\
Water & 78 & 12.5 & $13 \mathrm{~mm}$ \\
Ice $\left(0^{0} \mathrm{C}\right)$ & 3,2 & 0,0029 & $11,7 \mathrm{~m}$ \\
\hline
\end{tabular}


Even if pure ice is transparent to the microwave, other components show a different behaviour, like the fraction of water left unfrozen, that will absorb the microwave, which is actually why is quite easy to defrost food. At the same time, defrost parts, which are richer in liquid water than parts that are still frozen, will tend to absorb more energy, which will lead to a heterogeneous heating. Therefore, it is important not to defrost food at full power, to allow the transfer through conduction, time to achieve and balance temperatures. Dielectric properties are not the only determining factor for heating rate in a microwave oven. At the air-product interface, like other electromagnetic waves, microwaves are partly reflected by the surface of the product. The metal walls of the oven reflect almost entirely the energy of the microwave. Therefore, virtually all microwave power will eventually be absorbed by the product, even if more reflected wave passes are required.

This happens when the mass of the product is not very small (being less than $100 \mathrm{~g}$ ). For example, half a liter of oil will heat up faster than half a liter of water. When a product with an appreciable mass is in a microwave oven, its power becomes a limiting factor rather than food loss factor. For the example given above, the specific heat of the oil is twice as low as that of the water, so the oil will heat up twice as fast.

Applications of microwaves in the home use (for reheating, cooking, defrosting) are well known. In the food industry the use of microwaves is limited only by the cost of the needed equipment. Microwave applications in the food industry are numerous: dehydrationdrying, heating (blanching, pasteurization, baking, frying, defrosting), detoxification, clarification, structural modification, analytical determinations and others. The most common, however, are defrosting and vacuum drying. In general, microwave installations consist of microwave generators and a cavity in which the product is placed. The microwave generator made of a power supply and transformation into high voltage stabilized current, an electronic tube with speed modulator and a cooling system for the transmitter tube. Depending on the power required, a more powerful generator can be used or several lower power generators can be used. Depending on the size and nature of the products (liquids, pastes or solids), the cavity can be different oven-type or tunnel-type, with variable dimensions depending on the destination. Some examples of the use of microwaves will be presented below.

Defrosting meat and fish in the microwave is completely different from conventional defrosting, because, the heating is no longer done from the surface to the inside by conduction process, but takes place through all the product mass due to dielectric losses. Defrosting takes place very well up to -7 to $-5^{0} \mathrm{C}$, in the thermal center, becoming difficult between $-5^{\circ} \mathrm{C}$ and $0^{\circ} \mathrm{C}$. The non-uniformity of temperatures during defrosting is due to several causes:

- non-uniformity of the products, the thinner parts tend to defrost faster than the thick ones;

- non-uniformity of composition, fatter portions absorb less energy than the weakest, and salty parts absorb more energy than unsalted ones;

- non-uniformity of the microwave field.

Even with these observations, microwave defrosting is advantageous because it ensures better product quality (no juice is released and no product contamination occurs due to the speed of the process), the defrost surface is $1 / 10$ of the classic one [7].

Novel defrosting methods, such as dielectric heating [(Microwave (MW) and radio frequency (RF)] have been developed and recently used in domestic and industrial applications due to their volumetric heating capability, which has outstanding properties for food-quality preservation [11]. 
Applications for Microwave pasteurization and sterilization include both in-pack preservation of packed foods (e.g., ready-to-heat meals), that are heated continuously on a conveyor belt, batch-wise sterilization, as well as tubular in-flow sterilization of semi-fluid pumpable foods [12].

Microwave drying is 20 times faster than conventional drying processes. Other advantages are: there are significant savings in terms of constructed area, savings in electricity and steam, savings in the use of washing agents and maintenance. The quality of the products is improved, the appearance being more attractive and the pathogenic microorganisms (staphylococci and salmon) are eliminated more safely. Such installations are used for drying pasta and obtaining "chips". Microwaves can also be used to dehydrate vegetable products (carrots, onions), the dehydration duration being about 20 minutes, to reduce the humidity from $60 \%$ to $20 \%$ [7].

Drying is an important operation in the industry processes, usually involving heat applied to separate a liquid from a solid, leading to the evaporation of the liquid phase (water or another solvent). Drying is an energy-intensive activity and dryers are expensive pieces of equipment, therefore drying must be carried out as economically as possible. Utilizing microwaves, that uses a fundamentally different method of energy transfer, the drying process can be more advantageous compared to the conventional drying, due to the selective nature of interaction of the microwaves with the product to be dried [13].

Numerous researches (Table 2) on microwave-assisted air drying (MWAD) have been found in the literature on fruits and vegetables. Nistor et al. (2017) investigated the effect of several drying techniques like free convection $\left(50^{\circ} \mathrm{C}, 60^{\circ} \mathrm{C}, 70^{\circ} \mathrm{C}\right)$ and combination of free convection, forced convection $\left(40^{\circ} \mathrm{C}\right)$ along with microwave power $(315 \mathrm{~W})$ on physical and chemical properties of red beetroot. They reported that combined drying methods were more effective than the convective drying (CD) methods. The increase in drying rate and a decrease in drying time was obtained by increasing the drying temperature followed by microwave heating. The free convection $\left(60^{\circ} \mathrm{C}\right)$, followed by forced convection $\left(40^{\circ} \mathrm{C}\right)$ combined with microwave power $(315 \mathrm{~W})$ was the best drying method for beetroot [14].

Table 2. Numerous Researches Carried Out on Microwave-Assisted Air Drying [14]

\begin{tabular}{|l|c|c|}
\hline \multicolumn{1}{|c|}{ Product } & $\begin{array}{c}\text { Temperature }\left({ }^{\circ} \mathbf{C}\right) / \text { Air } \\
\text { Velocity (m/s) }\end{array}$ & $\begin{array}{c}\text { Power Rate (W/g) / } \\
\text { Power (W) }\end{array}$ \\
\hline Apple & $50^{\circ} \mathrm{C}, 60^{\circ} \mathrm{C}, 70^{\circ} \mathrm{C} / 2 \mathrm{~m} / \mathrm{s}$ & $0.1-1 \mathrm{~W} / \mathrm{g}$ \\
& $50^{\circ} \mathrm{C}, 60^{\circ} \mathrm{C}, 70^{\circ} \mathrm{C} / 2 \mathrm{~m} / \mathrm{s}$ & - \\
& $25^{\circ} \mathrm{C}, 30^{\circ} \mathrm{C}, 40^{\circ} \mathrm{C}, 50^{\circ} \mathrm{C} / 1 \mathrm{~m} / \mathrm{s}$ & $3,5,7,10 \mathrm{~W} / \mathrm{g}$ \\
& $30^{\circ} \mathrm{C}, 50^{\circ} \mathrm{C} / 2.5 \mathrm{~m} / \mathrm{s}$ & $0.5 \mathrm{~W} / \mathrm{g}$ \\
& $40^{\circ} \mathrm{C}, 60^{\circ} \mathrm{C}, 80^{\circ} \mathrm{C} / 0.5,1 \mathrm{~m} / \mathrm{s}$ & $0.5 \mathrm{~W} / \mathrm{g}$ \\
\hline Potato & $50^{\circ} \mathrm{C}, 60^{\circ} \mathrm{C}, 70^{\circ} \mathrm{C} / 2 \mathrm{~m} / \mathrm{s}$ & - \\
& $18^{\circ} \mathrm{C}, 65^{\circ} \mathrm{C} / 0.032 \mathrm{~m} / \mathrm{s}$ & $5,10 \mathrm{~W} / \mathrm{g}$ \\
& $45^{\circ} \mathrm{C} / 1.5 \mathrm{~m} / \mathrm{s}$ & $0.6 \mathrm{~W} / \mathrm{g}$ \\
\hline Carrot & $45^{\circ} \mathrm{C} / 1.5 \mathrm{~m} / \mathrm{s}$ & $0.6 \mathrm{~W} / \mathrm{g}$ \\
& $45^{\circ} \mathrm{C}, 60^{\circ} \mathrm{C} / 1.7 \mathrm{~m} / \mathrm{s}$ & $120,240 \mathrm{~W}$ \\
\hline Kiwifruit & $60^{\circ} \mathrm{C} / 1.29 \mathrm{~m} / \mathrm{s}$ & $210 \mathrm{~W}$ \\
\hline Olive & $100^{\circ} \mathrm{C}, 160^{\circ} \mathrm{C}, 225^{\circ} \mathrm{C} / 1 \mathrm{~m} / \mathrm{s}$ & $350,490,700 \mathrm{~W}$ \\
\hline Grape & $50^{\circ} \mathrm{C}$ & - \\
\hline Mushroom & $40^{\circ} \mathrm{C}, 60^{\circ} \mathrm{C}, 80^{\circ} \mathrm{C} / 0.5,1 \mathrm{~m} / \mathrm{s}$ & $0.5 \mathrm{~W} / \mathrm{g}$ \\
\hline Orange & $60^{\circ} \mathrm{C} / 2 \mathrm{~m} / \mathrm{s}$ & $0.17,0.36,0.69,0.88 \mathrm{~W} / \mathrm{g}$ \\
\hline Asparagus & $50^{\circ} \mathrm{C}, 60^{\circ} \mathrm{C}, 70^{\circ} \mathrm{C}$ & $2,4 \mathrm{~W} / \mathrm{g}$ \\
\hline Banana & $60^{\circ} \mathrm{C} / 1.45 \mathrm{~m} / \mathrm{s}$ & $350,490,700 \mathrm{~W}$ \\
\hline Pumpkin & $1 \mathrm{~m} / \mathrm{s}$ & $160,350 \mathrm{~W}$ \\
\hline
\end{tabular}


Vacuum dehydration. Microwaves can also be used for vacuum dehydration of the following products: soups, tomato extracts, vegetable proteins, meat and liver extracts, instant drinks, coffee extracts, concentrated fruit and vegetable juices, malt and hop extracts, beer must, (basic materials for the production of non - alcoholic beer), chocolate mass, vitamin extracts, intermediate materials for vitamins, enzymes and antibiotics, cultures of microorganisms.

Desensitization / disinsection / disinfection of agri-food products and reduction of their number of microorganisms. At a treatment of 9-10 seconds, molds (including spores) such as Fussarium graminearum, Aspergillus flavus, Penicillium patulum, Penicillium cyclopium, Tricothecium roseum, Rhizopus negricans and others can be destroyed. Research has shown that the anti-nutritional factors in some agri-food products, and especially those of a protein nature, can be inactivated by microwaves, as the food is heated through all their mass. Thermostable aflatoxins in peanut mass can be inactivated after 240 seconds of microwave treatment. Microwaves can also be used for lysis of microorganisms along with other processes such as the use of enzymes, chemicals, ultrasound, mechanical shocks, pressure or thermal shocks. The application of microwaves for 150 seconds leads to the thermolysis of various microbial cells, such as Trichoderma album, Geotrihum candium, Saccharomyces cerevisiae, favoring the release of cellular constituents, which is very important in obtaining plasmolysates, autolyses and protein hydrolysates.

Homogenization and stabilization of food emulsions. The analytical determinations where microwaves can be used are: the rapid determination of the dry matter in dairy products, molasses and preserving cans and the determination of the moisture content of granular and powdery products.

Microwave heating, as well as high (radio) frequency heating, is happening due to the transformation into heat by dielectric hysteresis of a part of the energy contained in the electromagnetic wave.

The microwave frequency range is between $3 \times 108-3 \times 1010 \mathrm{~Hz}$ and overlaps the telecommunications bands. In order to avoid jamming phenomena, certain frequency bands have been allocated for industrial, scientific and medical applications, also called ISM (Industrial, Medical and Scientific) frequencies. For Europe these frequencies are: 2450 $\mathrm{MHz}$ (the most used), $5800 \mathrm{MHz}$ and $22125 \mathrm{MHz}$ (most commonly used in the US). In the microwave field the wavelengths are smaller than the dimensions of the installations (for example, for $2450 \mathrm{MHz}, \lambda=12,2 \mathrm{~cm}$ ) and respects fundamental laws of propagation of electromagnetic waves. In the field of radio frequencies, the wavelengths are larger than the installation dimensions, and the laws of electromagnetism can still be applied in a quasistationary regime.

When heating dielectrics at high frequency or in "hyperfrequency", the depth of penetration is defined as the depth for which the power density is reduced for "e" times the value from the surface of the material that is under heating.

In radio frequency dielectric heating, the penetration depth is greater than $1 \mathrm{~m}$ and can reach several tens of meters, the heating being considered homogeneous throughout the material. In contrast, in the case of microwaves, the depth of penetration is much lower (for $2450 \mathrm{MHz}, \Delta=12 \mathrm{~mm}$ for water with a temperature of $12^{\circ} \mathrm{C}$ and $1200 \mathrm{~mm}$ for ice) and that is why it becomes an important factor [7]. Figure 1 presents the penetration depth. 


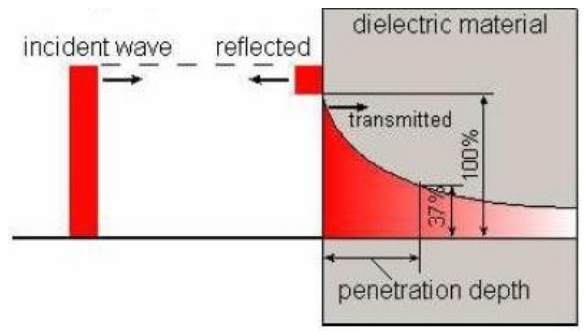

Fig. 1. Depth of penetration [9]

Microwaves are freely radiated into space by an electrode called an antenna and, in order for them to interact as efficiently as possible with the heating material, they must be guided and concentrated. A microwave heater will need the same three main components: the microwave generator, the waveguide, and the applicator [7].

\section{Technological equipments using microwaves for food preserving}

There are many companies that produce technical equipment for microwave treatment. In this regard, Mitech S.R.L. (Italy) is a manufacturer of ovens, equipment and industrial systems using microwave technology.

Microwave technology ensures a drastic decrease in treatment time in the following applications: BAKING - HEATING - DEFROST - DRYING - DEHYDRATION PASTEURIZATION OF PACKED AND UNPACKED PRODUCTS. The product range includes tunnel-type ovens, with continuous operation and batch furnace systems, with discontinuous operation, used in the industrial field, special ovens for laboratories, vacuum chambers and pressure autoclaves for scientific research.

Continuous tunnel ovens for the food industry are used to dry sweets and vegetable products through microwaves and hot air. Power may vary from 30 to $300 \mathrm{~kW}$.

In this regard, figure 2 presents a system used for drying sweets and vegetable products.

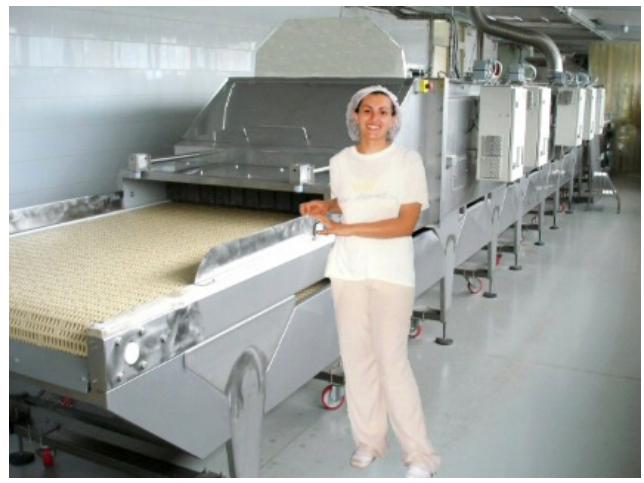

Fig. 2. System used for drying sweets and vegetable products [15]

Pasteurization of packed and unpacked products can be performed using microwaves and cold air. The power varies from 10 to $40 \mathrm{~kW}$. Figure 3 presents the system for pasteurization of packaged and unpackaged products. 


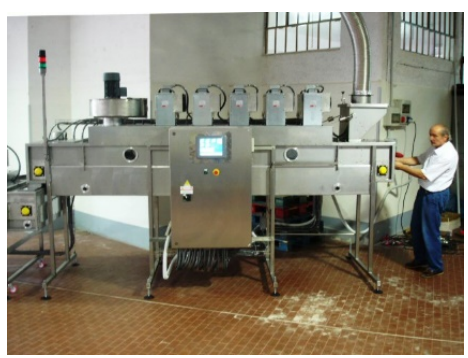

Fig. 3. The system for pasteurizing packed and unpacked products [15]

The company also produces detachable microwave chambers, made to facilitate transport and treatment at the place of using. Their power varies from 3 to $12 \mathrm{~kW}$. Figure 4 presents the mobile treatment system.

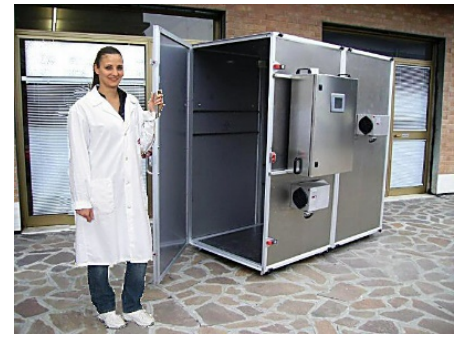

Fig. 4. Mobile treatment system [15]

For laboratory research use, special microwave ovens are sold, having the temperature controlled by an infrared thermometer. The power varies from 1 to $6 \mathrm{~kW}$. Figure 5 presents the laboratory research system.

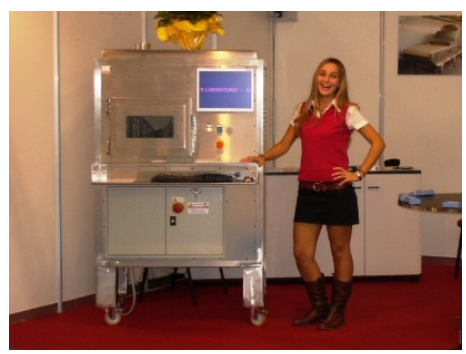

Fig. 5. Laboratory research system [15]

Emitech S.R.L. (Italy), sells patented technology named MISYA Agrofood, for disinfection and / or microwave drying treatments of food such as cereals, legumes, dried fruits.

The installation MISYA AH-36-T (fig. 6) operates continuously, using electromagnetic energy, at specific microwave frequencies, to treat legumes and cereals in the post-harvest phase.

This system is designed especially for continuous disinfestation of sensitive seeds. It consists of a shielded reverberation chamber, containing a slightly inclined tube in which the seeds are irradiated. The rotating tube, which allows the seeds to pass easily from inlet to outlet, also promotes constant mixing by reducing the risk of seed breakage and damage. 
The device has a maximum production capacity of $800 \mathrm{~kg} /$ hour with a power of 36 $\mathrm{kW}$. All process parameters (temperature, power, speed) are constantly monitored using a PLC-based electronic control and management system.
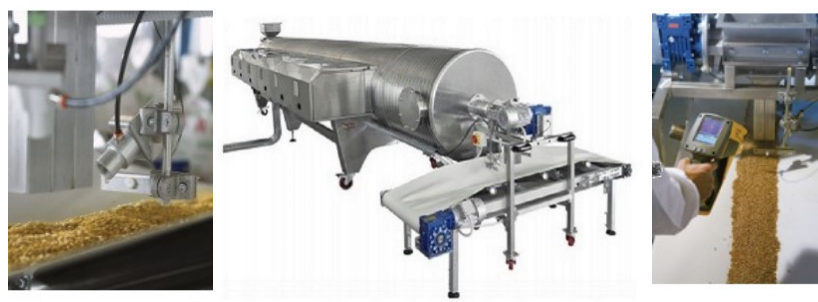

Fig. 6. The system MISYA AH-36-T [16]

Kerone (India) is a company that sells microwave installations, which can be used for blanching, pasteurization-sterilization, defrosting and drying. Figure 7 presents the microwave treatment system for various applications.

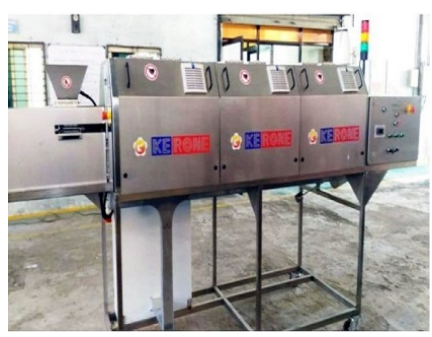

Fig. 7. Microwave treatment system for various applications [17]

\section{Conclusions}

The application of microwaves energy to enhance conventional or emerging food processing techniques is a viable alternative with high process efficiency and minimal changes to food quality attributes, when compared to traditional methods or usage of these technologies individually. These benefits can open the path for producing highly desirable food products for consumers and for increasing the adoption of microwave technology at commercial scale. The advantages of microwave assisted food processes are numerous.

Fast heating and high energy efficiency are the major advantages of using microwaves in food processing. Other advantages are: space saving, more efficient process control, selective heating and preservation of the nutritional quality of food.

Microwave applications in the food industry are numerous: dehydration-drying, heating (blanching, pasteurization, baking, frying, thawing), detoxification, clarification, structural modification, analytical determinations and others. The most common, however, are defrosting and vacuum drying.

Microwave defrosting is highly advantageous because ensures a better quality of the products (no juice is released and there is no contamination of the product due to the speed of the process), and the defrosting surface represents $1 / 10$ of the normal surface.

Microwave drying is 20 times faster than other conventional drying processes. 
This work was supported by a grant of the Ministry of Agriculture and Rural Development on the Sectoral Plan for Research and Development in the field of Agriculture and Rural Development ADER 2022, contract no. ADER 7.5.1.

\section{References}

1. B. Ioan, Preservation of agri-food products, Course support "Gheorghe Asachi" Tehnical University of Iaşi

2. F. Iordache, I. Gheorghe, V. Lazar, C. Curutiu, L. M. Ditu, A. M. Grumezescu, A., M. Holban, Food Preservation, Chapter: 9 Nanostructurated materials for prolonged and safe food preservation, A volume in Nanotechnology in the Agri-Food Industry, Pages 305-335, (2017)

3. E. Roşculete, Principles and methods for food preservation, UNIVERSITARIA Craiova Publishing House, Course, (2020)

4. C. Lungu, General principles of food preservation, Course, (2002)

5. B. G. Theresa, K. Fabian, O. Jörg - Hinrichs Innovative Food Science \& Emerging Technologies, New experimental set-up for testing microwave technology to continuously heat fouling-sensitive food products like milk concentrates, 65, (2020)

6. L. Gîtin, Special food processing technologies - "Dunarea de Jos" University of Galati, Course, (2008)

7. Project ADER 7.5.1., Research on the application of emerging technologies based on minimal processing methods in the industrialization of horticultural products, Sectoral Plan of the Romanian Ministry of Agriculture and Rural Development (2020)

8. T. F. Bedane, G. Quinn, J. G. Lyng - Innovative Food Processing Technologies, Chapter: 1.47 Microwave and Radio Frequency Processing of Animal-Related Food Products, Pages 743-766 (2021)

9. Flora-G. C. Ekezie et all, Trends in Food Science \& Technology, Microwave-assisted food processing technologies for enhancing product quality and process efficiency: A review of recent developments, (2017)

10. G. J. Swamya, K. Muthukumarappanb, Innovative Food Processing Technologies, Chapter: 1.46 Microwave and Radiofrequency Processing of Plant-Related Food Products, Pages 731-742, (2021)

11. Y. Lave, N. Sakai, Food Processing for Increased Quality and Consumption, Chapter 13 - Dielectric Defrosting of Frozen Foods, Pages 383-422, (2018)

12. B. W. Raaholt, Food Science, Microwave Pasteurization and Sterilization, (2020)

13. M. Radoiu, Chemical Engineering and Processing - Process Intensification, Microwave drying process scale-up, 155, (2020)

14. D. K. Verma, N. K. Mahanti, M. Thakur, S. K. Chakraborty and P. P. Srivastav Microwave Heating: Alternative Thermal Process Technology for Food Application, Chapter 2, 2020

15. http://www.mitech-srl.eu/public/it/index.html

16. https://emitech.it/en/misya-agrofood/

17. http://kerone.com/ 